19 Revue d'histoire du XIXe siècle

Société d'histoire de la révolution de 1848 et des

révolutions du XIXe siècle

19 | 1999

Aspects de la production culturelle au XIXe siècle

\title{
À propos du colloque sur les archives judiciaires
}

\section{(2) OpenEdition}

Journals

Édition électronique

URL : http://journals.openedition.org/rh19/186

DOI : 10.4000/rh19.186

ISSN : $1777-5329$

Éditeur

La Société de 1848

Édition imprimée

Date de publication : 1 décembre 1999

Pagination : 165-166

ISSN : 1265-1354

Référence électronique

«À propos du colloque sur les archives judiciaires », Revue d'histoire du XIXe siècle [En ligne], 19 | 1999,

mis en ligne le 26 août 2008, consulté le 15 septembre 2020. URL : http://journals.openedition.org/

rh19/186

Ce document a été généré automatiquement le 15 septembre 2020.

Tous droits réservés 


\section{À propos du colloque sur les archives judiciaires}

1 En décembre 1997 s'est tenu, pendant trois jours, un colloque international à Angers (Centre d'histoire des régulations et des politiques sociales-HIRES), coordonné par Frédéric Chauvaud et Jacques-Guy Petit, sur le thème l'histoire contemporaine et les usages des archives judiciaires (1800-1939). Archivistes, historiens, juristes et sociologues ont débattu sur le rôle, le statut et les usages des archives judiciaires. Les 120 participants $\mathrm{du}$ colloque étaient venus d'une vingtaine d'universités et de nombreux dépôts d'archives. Aux chercheurs et archivistes français s'étaient joints des Canadiens, des Belges, des Hongrois, des Roumains, des Suisses...

Le deux coordinateurs avaient retenu pour le colloque quatre entrées: les traces, les objets, les approches et enfin les problèmes que posent le traitement des archives judiciaires.

Les traces sont tantôt manuscrites, tantôt imprimées. Elles reflètent aussi bien l'évolution des savoirs socio-législatifs que les perceptions des magistrats ou des enfants envoyés dans les colonies pénitentiaires. Produites par différentes institutions ou ministères, elles posent les questions centrales du tri et de l'accès. Les discussions menées avec les archivistes ont montré l'importance de savoir quel cadre de classement il convient d'adopter et quelles sont les archives qu'il faut privilégier dans un contexte de justice de masse.

Le colloque d'Angers a ensuite proposé une gradation des objets de recherche, allant des plus " minuscules" aux plus "globaux". La documentation judiciaire a-t-elle permis de porter un nouveau regard sur des groupes et des catégories? Autorise-t-elle en particulier une histoire du quotidien, des tribunaux comme des justiciables? Se dessine également une histoire des réseaux professionnels et des réformateurs sociaux. Apparaît enfin une oubliée de l'histoire: la justice civile. Dans une France du XIXe siècle très procédurière, les fonds civils livrent une vaste documentation sur des sujets aussi divers que l'assistance judiciaire, l'état civil, l'accident...

Les participants furent ensuite invités à cerner les principales approches et méthodes de traitement des archives judiciaires, en particulier dans l'histoire quantitative. Les historiens français de la délinquance et de la répression ont privilégié une approche qualitative et critique du quantitatif. Quant aux sociologues, ils se sont attelés à la 
reconstitution de bases de données cohérentes, en Europe mais aussi au Canada. Les séries chiffrées apparaissent ainsi comme un instrument de mesure administrative, de contrôle de l'activité judiciaire, voire de contrôle social. Au-delà des approches, une réflexion importante fut également entreprise sur les usages des archives judiciaires dans l'histoire politique et institutionnelle.

Ces différents panoramas sur des archives judiciaires au service d'une histoire plurielle et complexe nécessitaient aussi de s'interroger sur les problèmes et les enjeux de la recherche. Certaines affaires judiciaires comme certaines périodes posent avec acuité les questions de confidentialité et de respect de la personne humaine, du secret et de la publicité, de la véracité et de la fantasmagorie. Les chercheurs devaient à nouveau tenter de cerner les règles du métier. Prolongeant la réflexion, le colloque d'Angers s'est demandé quelle grille d'intelligibilité mettre en place à propos d'une justice qui n'est pas seulement répressive mais aussi un lieu d'apaisement et d'étude des pratiques quotidiennes et culturelles.

Le colloque se termina par une table ronde, réunissant archiviste, sociologue, juriste, historien. Quatre questions ont servi de fil directeur aux débats : $1^{\circ}$ Existe-t-il une spécificité de l'histoire de la justice ? Le matériau judiciaire présente-t-il des " risques " particuliers, que ce soit du point de vue du traitement ou du point de vue de la déontologie du chercheur? $2^{\circ} \mathrm{Qu}$ 'en est-il de la pluridisciplinarité ou de l'interdisciplinarité dans le domaine de l'histoire de la justice et du droit ? $3^{\circ}$ Comment expliquer les différences entre le développement de la recherche relative à la justice pénale et les faiblesses des travaux se rapportant à la justice civile pour ne pas parler de la justice administrative ? $4^{\circ}$ Quels sont les chantiers, les approches, les thèmes ou les objets qui semblent aujourd'hui prioritaires et novateurs dans le domaine de l'histoire de la Justice?

Il n'y eut pas de réponses définitives à toutes ces questions mais les débats montrèrent la nécessité d'un travail collégial qui dépasse les périodes et les disciplines. Le colloque d'Angers, marque donc une étape importante et sera, une fois les actes publiés avec le concours de la Mission de recherche droit et justice, le livre de référence sur les usages des archives judiciaires pour la période contemporaine. 